\title{
Does Liolaemus lemniscatus eavesdrop on the distress calls of the sympatric weeping lizard?
}

\author{
Lydia J. M. Fong ${ }^{1}\left(\mathbb{0} \cdot\right.$ Fernando Navea ${ }^{2} \cdot$ Antonieta Labra $^{3}($
}

Received: 9 April 2020 / Accepted: 27 July 2020 / Published online: 4 August 2020

(c) The Author(s) 2020

\begin{abstract}
For a prey, its best ticket to stay alive is to get early and accurate information on predation risk and so, escape from predation at low cost. Some prey species have evolved the ability to eavesdrop signals intended for others, which contain information on predation risk. This is the case for the vocalizations produced by prey species when interacting with predators. Although primarily studied in birds and mammals, eavesdropping on vocal signals has been recorded in some lizard species. Here, we explored whether the lizard Liolaemus lemniscatus eavesdrops on the distress calls of its sympatric species, the Weeping lizard (L. chiliensis). Individuals of the Weeping lizard respond to these calls by displaying antipredator behaviours (i.e., reduced movement), and individuals of $L$. lemniscatus may potentially display similar defences if they decode the information contained in these calls. Our playback experiments showed that individuals of L. lemniscatus responded to the sound stimuli (distress calls and white noise), reducing their activity, but they did not discriminate between these two stimuli, suggesting that L. lemniscatus does not eavesdrop on the distress calls of its sympatric lizard species. We discuss some hypotheses to explain the lack of eavesdropping by L. lemniscatus on the Weeping lizard distress calls.
\end{abstract}

Keywords Antipredator response $\cdot$ Liolaemus chiliensis $\cdot$ Predation risk $\cdot$ Chemical exploration $\cdot$ Vocal signals

\section{Introduction}

In a predator-prey interaction, the challenge for prey is to avoid being predated, which constitutes the selective pressure for the evolution of defences or antipredator mechanisms (Caro 2005). As presented by Endler (1986), these defences can interrupt the predation event in any of its stages: detection, identification, approach, subjugation, and prey consumption. Defences may serve different functions depending on which stage of the predation event it interferes at. For example, defensive vocalizations can interrupt early this predation event (i.e., alarm calls) or late (i.e., distress

Antonieta Labra

a.1.1illo@ibv.uio.no

1 Department of Zoology, University of British Columbia, Vancouver, Canada

2 Facultad de Ciencias, Departamento de Biología, Laboratorio de Neurobiología y Biología del Conocer, Universidad de Chile, Santiago, Chile

3 Centre for Ecological and Evolutionary Synthesis (CEES), Department of Biosciences, University of Oslo, Oslo, Norway calls). This is better understood by the definition given by Magrath et al. (2015a): an individual produces an alarm call when the presence of a predator is detected, whereas a distress call is produced after an individual has had physical contact with a predator through capture or attack.

Defensive vocalization have been primarily studied in birds and mammals (Caro 2005), and data indicate that alarm calls usually act as warning signals to conspecifics (Klump and Shalter 1984; Caro 2005), while distress calls can have different functions: startle the predator, alert secondary predators, and/or warn conspecifics of predation risk (Högstedt 1983; Neudorf and Sealy 2002). As warning signals, both call types may not only elicit antipredator responses in conspecifics, but also in heterospecifics, which may eavesdrop on these calls to reduce their own predation risk at low cost (Magrath et al. 2015a). Eavesdropping can be facilitated considering that the call structure, at least of the distress calls, appears conserved across various taxa (e.g., Högstedt 1983; Russ et al. 2004; Lingle et al. 2012), and thus, different prey species may decode the information about the nearby threat and act accordingly (Aubin 1991; Huang et al. 2018). In the case of alarm calls, evidence indicate that eavesdropping is possible if calls have 
similar acoustic structure (Fallow et al. 2013; Dutour et al. 2020). Research on eavesdropping has been mostly focused on alarm calls (Caro 2005), such as the study on the burrowing owl (Athene cunicularia) where the individuals display antipredator behaviours when listening the alarm calls of black-tailed prairie dogs (Cynomys ludovicianus), which vocalize to warn kin when danger is spotted (Bryan and Wunder 2014). However, eavesdropping on heterospecific distress calls has been observed, for example, in different bat species that respond to calls with mobbing behaviours (Fenton et al. 1976; Russ et al. 2004).

As presented, most of the known call eavesdroppers are also vocalizing species (birds and mammals; Magrath et al. 2015a). Yet the first case of eavesdropping by a non-vocal species was reported by Vitousek et al. (2007), showing that the marine iguana (Amblyrhynchus cristatus) eavesdrops on the alarm calls of the Galapagos mockingbird (Nesomimus parvulus). Since this report, eavesdropping has been reported in three other non-vocal lizards: two species from Madagascar, Zonosaurus laticaudatus and Oplurus cuvieri cuvieri (Ito and Mori 2010; Ito et al. 2017) that display antipredator behaviours when perceiving mobbing calls (a type of alarm call; Magrath et al. 2015a) of the Madagascar paradise flycatcher (Terpsiphone mutata), which is also eavesdropped by one vocal lizard, Phelsuma kochi (Ito et al. 2013). In addition, Emoia cyanura, from the French Polynesia, displays antipredator behaviours after hearing the alarm calls of the red-vented bulbul, Pycnonotus cafer (Fuong et al. 2014).

Considering that different non-vocal lizards eavesdrop on alarm calls, here we explored whether the non-vocal lizard Liolaemus lemniscatus eavesdrops on the distress calls emitted by a sympatric congeneric species, the Weeping lizard, L. chiliensis. Individuals of this species emit distress calls when they are captured by a predator, and while the lizard struggle to escape, attempting to bite, it vocalizes with the mouth open (Carothers et al. 2001; Labra et al. 2013). Conspecifics respond to these calls with antipredator behaviours, such as long periods of immobility (Hoare and Labra 2013; Labra et al. 2016; Ruiz-Monachesi and Labra 2020). This response should lower the risk of detection from predators, because different predators detect prey by their movements (e.g., Shine and Sun 2003; Nishiumi and Mori 2015). In addition, data from one of the main predator of the Weeping lizard, the snake Philodryas chamissonis, show that snakes reduce significantly their activity when they are exposed to the Weeping lizard distress calls (Hoare and Labra 2013), which can provide opportunities for a vocalizing trapped lizard to escape. Although snakes are almost deaf (Young 2003), they can detect vibrations through the substrate (Young and Morain 2002). The Weeping lizard can be found on the ground, around bushes or perched on shrubs, while $L$. lemniscatus is mainly a ground-dwelling species (Jaksić and
Núñez 1979; Mella 2017), which sometimes can be found on the ground at close distances to the weeping lizard $(<0.5 \mathrm{~m}$; pers. obs.). This proximity may provide opportunities for L. lemniscatus to be exposed to the calls of the Weeping lizard, and decoding the information of these calls can be advantageous for L. lemniscatus since both Liolaemus species share predators (i.e., raptors, snakes; Mella 2017). Since both Liolaemus species display similar responses to scents of a shared snake predator, i.e., reduction of activity (Labra and Niemeyer 2004; Labra and Hoare 2015), it is possible that individuals of L. lemniscatus may also display antipredator behaviours when they hear the distress calls of the Weeping lizard, and in doing so, they reduce their own predation risk.

\section{Materials and methods}

We collected 13 individuals of $L$. lemniscatus [5 nonpregnant $\bigcirc, 8 \hat{\circ}$; mean snout-vent length $45 \pm 13$ (SE) $\mathrm{mm}]$ in the summer of 2015, at Naltahua $(-33.725233 \mathrm{~S}$, - $70.988923 \mathrm{~W}$ ), Central Chile, after the breeding season (Ibarguengoytia 2008). We transported lizards to the laboratory and housed them individually in plastic enclosures $(44.5 \times 32 \times 25 \mathrm{~cm})$ with hermetic lids partially replaced by a plastic mesh to allow extra climbing surface. The front of the enclosures also had an opening $(10 \times 5 \mathrm{~cm})$ covered with the plastic mesh. We furnished enclosures with a pot to keep constant water supply, an inverted tile used as shelter and basking place, a wooden stick used as perch, and the floor had a sand layer of $3 \mathrm{~cm}$. Lizards were maintained in an indoor vivarium kept with conditions similar to those recorded in the field during hot summer days, i.e., temperatures ranging between $33{ }^{\circ} \mathrm{C}$ and $12{ }^{\circ} \mathrm{C}$ and a $13: 11 \mathrm{~L}: \mathrm{D}$ photoperiod. Animals received food (mealworms dusted with vitamins) three times per week and they remained undisturbed at least 1 week prior to the experiments, except for feeding. At the end of the experiments, we returned the lizards to their georeferenciated collecting points.

\section{Experiments}

We exposed all individuals to each treatment (stimulus) only once using a counterbalance design (see Hoare and Labra 2013). The three stimuli were: 1 -distress call of the L. chiliensis, 2-white noise, and 3-silence. The acoustic stimuli were made with Adobe Audition 3. To control for the variability of the distress calls (e.g., dominant frequency, duration, frequency-modulated pattern), we made one synthetic distress call (e.g., Hoare and Labra 2013; Ruiz-Monachesi and Labra 2020), using the mean values of calls emitted by 13 individual $L$. chiliensis from the same locality as $L$. 
lemniscatus (for more details of how vocalizations were obtained see Labra et al. 2013).

The synthetic call had a downward frequency-modulated pattern, the most commonly recorded in this species (Fig. 1a; Labra et al. 2013), with five harmonics built using the frequencies and intensities measured at the beginning and end of each harmonic. The fundamental frequency was from 2.7 to $2.4 \mathrm{kHz}$ at baseline to the end (Fig. 1b). The call duration was of $180 \mathrm{~ms}$, which was the only parameter for which we did not use the mean, but in this case, the longest call duration with the downward pattern, to ensure that individuals of L. lemniscatus heard the calls. The white noise had the same duration of the call, and it was the acoustic control of the call. For the silence treatment, we prepared a record with a silence of the same duration as the sound stimuli. Based on the intensities measured when calls were recorded, the acoustic stimuli were set to $51 \mathrm{~dB}$ RMS SPL, measured at the center of the experimental enclosure. Stimuli were reproduced using a Behringer® loudspeaker placed on the floor, $15 \mathrm{~cm}$ in front of the window of the experimental enclosure. We reproduced the stimuli using an iPod Nano A1320 that was connected to a NAD Electronics 3020i amplifier and this, to a loudspeaker.

For each trial, the focal lizard was removed from its enclosure and held in a cloth bag for 10 min to reduce handling related stress (Labra 2011). Thereafter, the bag was carefully opened on the top of the experimental enclosure, similar to the maintenance enclosure but with only clean sand. The focal lizard was allowed to move freely into the enclosure, and once it was on the enclosure floor, we removed the bag and closed the enclosure with a sheet of glass $(37 \times 30 \mathrm{~cm})$ instead of the

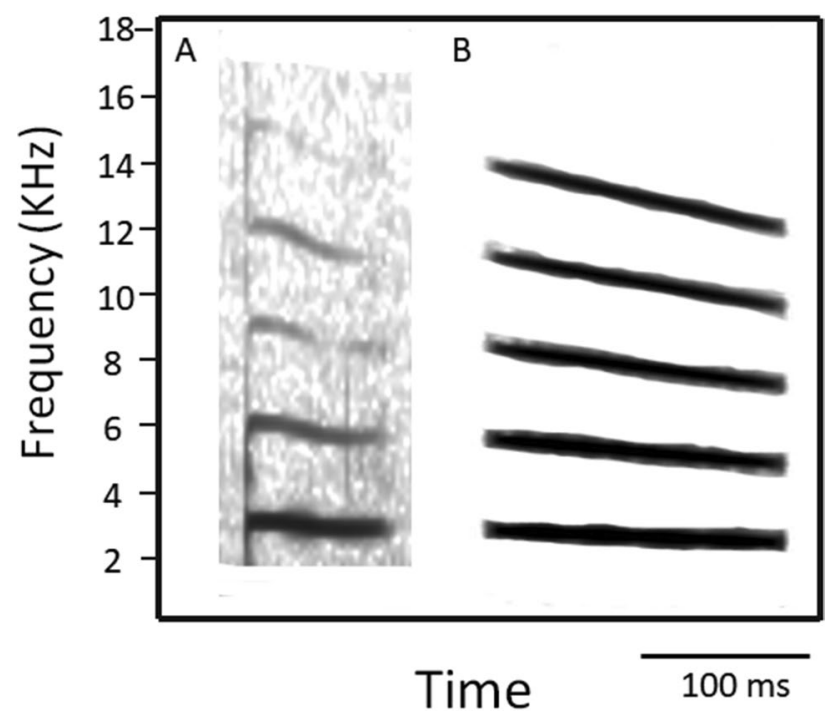

Fig. 1 Spectrograms of distress calls: a natural call emitted by a female of Liolaemus chiliensis (90 mm in snout-vent length). b Synthetic distress call built using the average values of calls emitted by 13 individuals of Liolaemus chiliensis plastic lid. Before a new trial, the glass was cleaned with ethanol (95\%), the enclosure was washed with soap, and the sand was discarded and replaced by new sand. Using this protocol, we eliminated any chemical traces of the focal individual that may affect the behaviour of the new one. Because variations in body temperature can induce variation in behaviour, we kept the experimental area at $35^{\circ} \mathrm{C}$. Then, at the end of the trial, we took the cloacal temperature of the focal lizard, and if it was not close to the selected mean body temperature of the species $\left(35 \pm 2{ }^{\circ} \mathrm{C}\right.$; Labra et al. 2009), the trial was discarded and repeated another day. Thereafter, the focal lizard was placed back in its enclosure and had an intertrial resting period of at least 3 days.

The lizard's behaviour was filmed for $10 \mathrm{~min}$ and $2.72 \mathrm{~s}$ with a Panasonic HDC-TM20 camcorder located $60 \mathrm{~cm}$ above the experimental enclosure. We began filming after the lizard started the chemical exploration by tongue flicking (Labra 2011). Experiments had three stages (see RuizMonachesi and Labra 2020): (1) pre-stimulus, the first 5 min after starting the recording. (2) Stimulus, the period where the stimulus was presented which lasted 2.72 s. (3) Poststimulus, the last $5 \mathrm{~min}$ after stimulus. The whole stimulus was composed of three identical elements (sounds or silence) separated by two silent periods, which were within the range of previously recorded silence periods. A third silence period was placed at the beginning of the stimulus. From the videotape recordings, we determined two behavioural variables during the pre- and post-stimulus periods: chemical exploration (tongue flick) and total displacement. A third variable was recorded during the post-stimulus period, the latency post-stimulus (for definitions of the variables see Table 1). The short duration of the stimulus (2.72 s) precluded analysing any behaviours during this period.

\section{Statistical analysis}

We determined the induced behavioural changes in the chemical exploration and total displacement exhibited by lizards due to the stimuli, by computing the pre- to post-stimulus difference (i.e., post-stimulus values minus pre-stimulus values). These differences and the latency post-stimulus were normally distributed, and they were analysed using a one-way general linear model with repeated measures, followed by the a posteriori Fisher LSD tests. The residuals of the three variables appeared homoscedastic and normally distributed.

\section{Results}

The acoustic stimuli did not modulate the changes in the chemical exploration, i.e., tongue flicks (Fig. 2a); lizards showed similar changes across all treatments. However, the 
Table 1 Behaviours recorded from videotapes for lizards. The first behaviour is measured as the number of times and the remainder as the total time that animals exhibited these behaviours

\begin{tabular}{lll}
\hline Behaviour & Description & Reference \\
\hline $\begin{array}{l}\text { Chemical exploration } \\
\left(\mathrm{N}^{\circ} \text { Tongue-flicks) }\right.\end{array}$ & Sample the chemicals in the environment by tongue flicking or gaping & (Labra et al. 2002; Labra 2006) \\
$\begin{array}{l}\text { Total displacement (s) } \\
\text { Latency post-stimulus } \\
\text { (s) }\end{array}$ & $\begin{array}{l}\text { Total time that lizards were moving (e.g., walk, change of the position), and } \\
\text { made escape attempts, which includes running movements, rub the tip of } \\
\text { the snout against the walls of the enclosure, climb the walls or dig in the } \\
\text { substrate } \\
\text { Period between the end of the stimulus and the onset of any behaviour (tongue } \\
\text { flick or displacement) }\end{array}$ & (Font and Desfilis 2002; Labra 2006) \\
\hline
\end{tabular}

total displacement time and the latency post-stimulus were modulated by the stimuli; lizards exposed to sounds, distress calls or white noise, exhibited a significant reduction of the total displacement time (Fig. 2b), and they took longer to restore their activity (Fig. 2c), as compared to the silence treatment. There were no differences between the two sound treatments (call vs. noise).

\section{Discussion}

We explored whether L. lemniscatus responds to the distress calls emitted by the sympatric and congeneric Weeping lizard. Data show that individuals behave similarly when they were exposed to distress calls and white noise, showing no signs of discrimination between these two sound stimuli. This suggests that any "scary" sound may activate antipredator behaviours in L. lemniscatus, and that the distress calls of the Weeping lizard do not contain any special information for L. lemniscatus to eavesdrop on.

Why does not $L$. lemniscatus eavesdrop on the distress calls of the Weeping lizard? We propose three non-mutually exclusive hypotheses. The first one deals with the call characteristics of the "caller species". The reported "caller species", mainly birds, but also mammals (i.e., vocal species; Magrath et al. 2015a), depend heavily on acoustic communication (Marler and Slabbekoorn 2004), and their calls have an active space of at least 80-200 m, depending on the environmental conditions (e.g., Brenowitz 1982; Brown and Schwagmeyer 1984). Therefore, an individual can be as far as $200 \mathrm{~m}$ and yet benefits by eavesdropping on calls. Although there is no data on the active space of the distress calls of the Weeping lizard under natural condition, under laboratory conditions the intensity of these calls, measured at $15 \mathrm{~cm}$ from the lizard is $51 \mathrm{~dB}$ SPL (unp. data), and Carothers et al. (2001) indicated that under these experimental conditions a human can hear calls from $\sim 3 \mathrm{~m}$. It is unclear from how far the Weeping lizard can hear these calls, as it is for species such as geckos, a taxon more vocal than lizards (Colafrancesco and Gridi-Papp 2016). For example, the determination of how far the calls of Gekko japonicas are audible is based on human perception (Jono and Inui 2012). Being careful in making inferences on lizard perception from human perception, we suggest that potentially the more reduced active space of the Weeping lizard distress calls, compared to those of the bird and mammal calls, may impose important restrictions to an eavesdropper; it should always be at close distance to a caller individual. In addition, the wider active space of the vocalizations of the "vocal caller species" also dictates that eavesdroppers can normally be exposed to calls more frequently, because they can hear diverse callers from different areas. This can explain why the Madagascar paradise flycatcher, which seems to have a high predation rate (Mizuta 2000) and individuals emit loud alarm calls under predation risk (Mizuta 2002), has at least three lizard species, two of them non-vocal species, that eavesdrop on its calls (Ito and Mori 2010; Ito et al. 2013, 2017). We propose that the call characteristics of the distress calls of the Weeping lizard determine that L. lemniscatus does not have enough exposure to these calls to evolve eavesdropping. Moreover, individuals of the Weeping lizard are spread out between 3 and $10 \mathrm{~m}$ (pers. obs.) and under predation risk, they escape toward the inside of the bushes (pers. obs.), while L. lemniscatus escapes toward grassy patches (Jaksić and Núñez 1979). The fact that individuals of both species escape to different areas would lead to a greater distance and less exposure of L. lemniscatus to the distress calls of the Weeping lizard, if for example, one individual was finally trapped inside a bush. Therefore, even though individuals of both species are found occasionally at close proximity, this does not guarantee that $L$. lemniscatus has had enough exposition to the Weeping lizard calls to evolve as an eavesdropper species, as compared with those lizard eavesdroppers from vocal species (Ito and Mori 2010; Ito et al. 2013, 2017; Fuong et al. 2014).

Learning can be another factor involved in eavesdropping. Some eavesdropping species require a learning process, as demonstrated with the wild superb fairy-wrens, Malurus cyaneus (Magrath et al. 2015b), in which individuals were able to recognize unfamiliar sounds as a form of 
Fig. 2 The mean (+/-SE) of the three responses of Liolaemus lemniscatus when exposed to the distress calls of the L. chiliensis, white noise, or silence. The changes in the behavior as consequence of the stimulus (post-stimulus minus pre-stimulus) are shown for: a chemical exploration and $\mathbf{b}$ total displacement. The last behavior, c latency post-stimulus is the time since lizards re-start their behavior after the stimulus
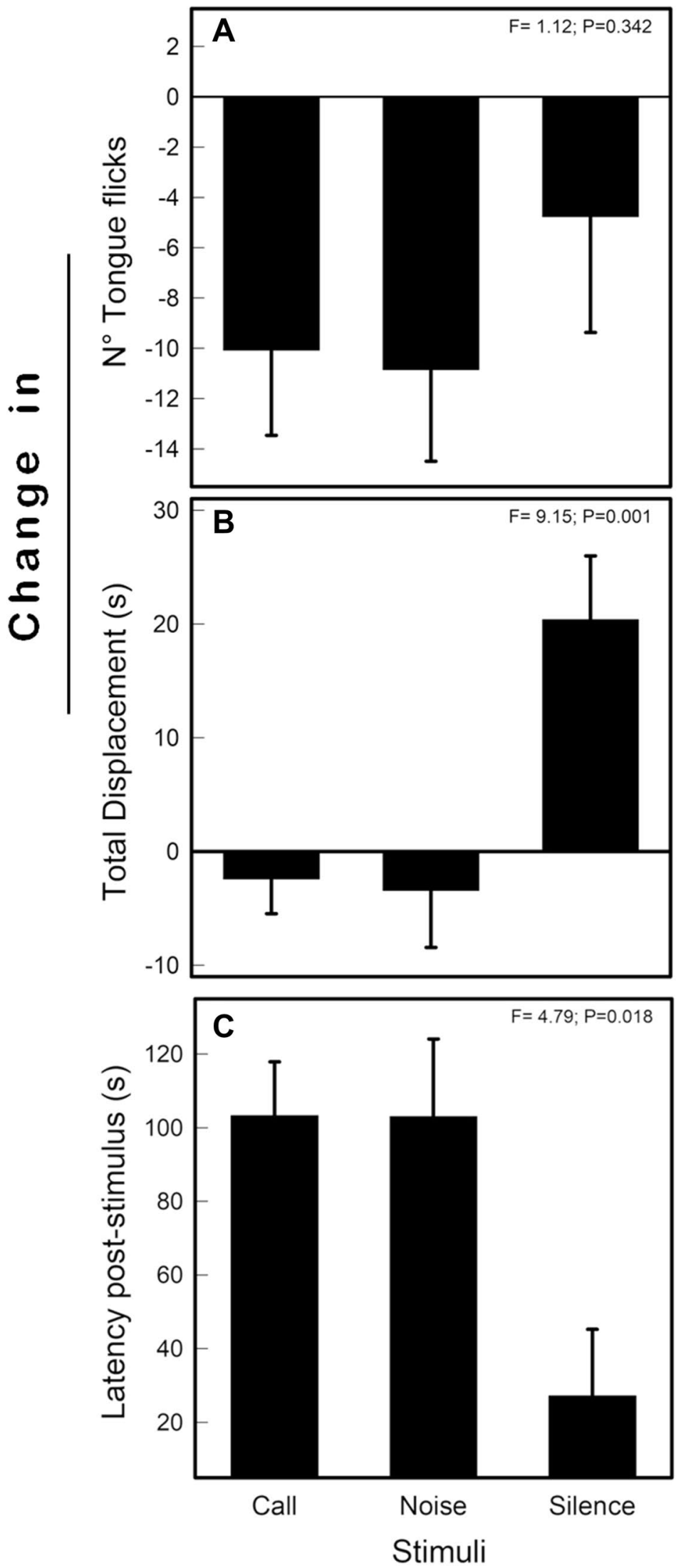
alarm calling when associated with predator presence. In the experiment conducted by Potvin et al. (2018), there was a selective pressure for the superb fairy-wrens to learn to associate sounds as warning cues and then express antipredator behaviour, despite the novelty of these sounds. However, individuals only learnt how to eavesdrop after a certain amount of exposure, displaying most of the antipredator behaviours after a week of experience. In the case of the white-browned scrubwrens, Sericornis frontalis, adults only displayed antipredatory responses to heterospecific alarm calls if they were exposed to these calls either as fledglings or adults (Haff and Magrath 2013). We ignore the ability of L. lemniscatus to learn the association between distress calls and predation. The only information about learning in Liolaemus comes from $L$. tenuis, for which data indicate that individuals can learn to recognize a conspecific, but after 20 days without interaction with that individual, the recognition is lost (Trigosso-Venario et al. 2002). However, considering that for other lizard species it was shown that individuals require continuous training to learn (e.g., Day et al. 2003; Noble et al. 2014), selection is unlikely to act on $L$. lemniscatus without the opportunities to learn to eavesdrop. There are in fact, few empirical studies on the evolutionary pressures for heterospecifics to learn to eavesdrop on distress calls and the rate at which it occurs (Pollock et al. 2017).

Finally, it is also possible that L. lemniscatus does not eavesdrop the distress calls of the Weeping lizard because these calls have evolved relatively recent, and L. lemniscatus has not been exposed enough to evolve eavesdropping on these calls. The molecular phylogeny provided by Esquerre et al. (2019) shows that the Weeping lizard, and so the distress calls, occurred much later than the split of these two species. In addition, the only Liolaemus species for which there are clear evidence of vocalization is in the Weeping lizard (Reyes-Olivares and Labra 2017), indicating that L. lemniscatus has not being historically exposed to distress calls of any other Liolaemus species.

In summary, we found that $L$. lemniscatus only discerns sounds vs. silence, without differentiating between distress calls and white noise. The discussed hypotheses have in common the relatively low exposition of L lemniscatus to the distress calls, resulting in a non-existent selective pressure for this species to evolve as an eavesdropper of the distress calls of the Weeping lizard.

Acknowledgements Open Access funding provided by University of Oslo (incl Oslo University Hospital). The study was authorized by SAG (Resolution No.7413) and by the Scientific Ethics Committee of the Faculty of Medicine, University of Chile. We thank to two anonymous reviewers for their valuable comments to the first version of this manuscript, to M. Weymann, C. Reyes-Olivares and H. Díaz for their field assistance and to F. Moreno-Gómez for help with the acoustic stimuli and the amplifier for the playbacks. L.J.M. Fong thanks the University of British Columbia for supplementary funding. This study was supported by Fondecyt 1120181 (AL).
Open Access This article is licensed under a Creative Commons Attribution 4.0 International License, which permits use, sharing, adaptation, distribution and reproduction in any medium or format, as long as you give appropriate credit to the original author(s) and the source, provide a link to the Creative Commons licence, and indicate if changes were made. The images or other third party material in this article are included in the article's Creative Commons licence, unless indicated otherwise in a credit line to the material. If material is not included in the article's Creative Commons licence and your intended use is not permitted by statutory regulation or exceeds the permitted use, you will need to obtain permission directly from the copyright holder. To view a copy of this licence, visit http://creativecommons.org/licenses/by/4.0/.

\section{References}

Aubin T (1991) Why do distress calls evoke interspecific responses? An experimental study applied to some species of birds. Behav Proc 23:103-111

Brenowitz EA (1982) The active space of red-winged blackbird song. J Comp Physiol 147:511-522

Brown C, Schwagmeyer P (1984) The vocal range of alarm calls in thirteen-lined ground squirrels. Z Tierpsychol 65:273-288

Bryan RD, Wunder MB (2014) Western burrowing owls (Athene cunicularia hypugaea) eavesdrop on alarm calls of black-tailed prairie dogs (Cynomys ludovicianus). Ethology 120:180-188

Caro TM (2005) Antipredator defenses in birds and mammals. The University of Chicago Press, London

Carothers JH, Groth JG, Jaksić FM (2001) Vocalization as a response to capture in the central Chilean lizard Liolaemus chiliensis (Tropiduridae). Stud Neotrop Fauna Environ 36:93-94

Colafrancesco KC, Gridi-Papp M (2016) Vocal sound production and acoustic communication in amphibians and reptiles. In: Suthers RA, Fitch WT, Fay RR, Popper AN (eds) Vertebrate sound production and acoustic communication (Suthers R. Springer, Cham, pp 51-82

Day LB, Ismail N, Wilczynski W (2003) Use of position and feature cues in discrimination learning by the whiptail lizard (Cnemidophorus inornatus). J Comp Psychol 117:440

Dutour M, Suzuki TN, Wheatcroft D (2020) Great tit responses to the calls of an unfamiliar species suggest conserved perception of call ordering. Behav Ecol Sociobiol 74:1-9

Endler JA (1986) Defense against predators. In: Feder ME, Lauder GV (eds) Predator-prey relationships: perspecives and approaches from the study of lower vertebrates. University of Chicago Press, Chicago, Illinois, pp 109-134

Esquerré D, Brennan IG, Catullo RA, Torres-Pérez F, Keogh JS (2019) How mountains shape biodiversity: the role of the Andes in biogeography, diversification, and reproductive biology in South America's most species-rich lizard radiation (Squamata: Liolaemidae). Evolution 73:214-230

Fallow PM, Pitcher BJ, Magrath RD (2013) Alarming features: birds use specific acoustic properties to identify heterospecific alarm calls. Proc Royal Soc B 280:20122539

Fenton MB, Belwood JJ, Fullard JH, Kunz TH (1976) Responses of Myotis lucifugus (Chiroptera: Vespertilionidae) to calls of conspecifics and to other sounds. Can J Zool 54:1443-1448

Font E, Desfilis E (2002) Chemosensory recognition of familiar and unfamiliar conspecifics by juveniles of the Iberian wall lizard, Podarcis hispanica. Ethology 108:319-330

Fuong H, Keeley KN, Bulut Y, Blumstein DT (2014) Heterospecific alarm call eavesdropping in nonvocal, white-bellied copperstriped skinks, Emoia cyanura. Anim Behav 95:129-135 
Haff TM, Magrath RD (2013) Eavesdropping on the neighbours: fledglings learn to respond to heterospecific alarm calls. Anim Behav $85: 411-418$

Hoare M, Labra A (2013) Searching for the audience of the weeping lizard's distress call. Ethology 119:860-868

Högstedt G (1983) Adaptation unto death: function of fear screams. Am Nat 121:562-570

Huang X, Metzner W, Zhang K, Wang Y, Luo B, Sun C, Jiang T, Feng J (2018) Acoustic similarity elicits responses to heterospecific distress calls in bats (Mammalia: Chiroptera). Anim Behav 146:143-154

Ibarguengoytia NR (2008) Estrategias reproductivas en reptiles. In: Vidal MA, Labra A (eds) Herpetología de Chile. Science Verlag, Santiago, Chile, pp 391-425

Ito R, Ikeuchi I, Mori A (2013) A day gecko darkens its body color in response to avian alarm calls. Curr Herpetol 32:26-33

Ito R, Mori A (2010) Vigilance against predators induced by eavesdropping on heterospecific alarm calls in a non-vocal lizard Oplurus cuvieri cuvieri (Reptilia: Iguania). Proc Royal Soc B 277:1275-1280

Ito R, Randrianarisoa T, Mori A (2017) How common is heterospecific evesdropping in lizards? Test using a Madagascan gerrhosaurid. Curr Herpetol 36:46-53

Jaksić FM, Núñez H (1979) Escaping behavior and morphological correlates in two Liolaemus species of central Chile (Lacertilia: Iguanidae). Oecologia 42:119-122

Jono T, Inui Y (2012) Secret calls from under the eaves: Acoustic behavior of the Japanese house gecko, Gecko japonicus. Copeia 2012:145-149

Klump GM, Shalter MD (1984) Acoustic behavior of birds and mammals in the predator context. I. Factors affecting the structure of alarm signals. II. The functional-significance and evolution of alarm signals. Z Tierpsychol 66:189-226

Labra A (2006) Chemoreception and the assessment of fighting abilities in the lizard Liolaemus monticola. Ethology 112:993-999

Labra A (2011) Chemical stimuli and species recognition in Liolaemus lizards. J Zool 285:215-221

Labra A, Hoare M (2015) Chemical recognition in a snake-lizard predator-prey system. Acta Ethol 18:173-179

Labra A, Niemeyer HM (2004) Variability in the assessment of snake predation risk by Liolaemus lizards. Ethology 110:649-662

Labra A, Pienaar J, Hansen TF (2009) Evolution of thermal physiology in Liolaemus lizards: adaptation, phylogenetic inertia, and niche tracking. Am Nat 174:204-220

Labra A, Reyes-Olivares C, Weymann M (2016) Asymmetric response to heterotypic distress calls in the lizard Liolaemus chiliensis. Ethology 122:758-768

Labra A, Escobar CA, Aguilar PM, Niemeyer HM (2002) Sources of pheromones in the lizard Liolaemus tenuis. Rev Chil Hist Nat 75:141-147

Labra A, Silva G, Norambuena F, Velásquez N, Penna M (2013) Acoustic features of the weeping lizard's distress call. Copeia 2013:206-212

Lingle S, Wyman MT, Kotrba R, Teichroeb LJ, Romanow CA (2012) What makes a cry a cry? A review of infant distress vocalizations. Curr Zool 58:698-726

Magrath RD, Haff TM, Fallow PM, Radford AN (2015) Eavesdropping on heterospecific alarm calls: from mechanisms to consequences. Biol Rev 90:560-586
Magrath RD, Haff TM, McLachlan JR, Igic B (2015) Wild birds learn to eavesdrop on heterospecific alarm calls. Curr Biol 25:2047-2050

Marler P, Slabbekoorn H (2004) Nature's music. Elsevier Academic Press, California, USA, The science of birdsong

Mella J (2017) Guía de Campo. Reptiles de Chile. Tomo I. Zona Central. Alvinpress, Santiago, Chile

Mizuta T (2000) Intrusion into neighboring home range by male Madagascar paradise flycatchers, Terpsiphone mutata: a circumstantial evidence for extra-pair copulation. J Ethol 18:123-126

Mizuta T (2002) Predation by Eulemur fulvus fulvus on a nestling of Terpsiphone mutata (Aves: Monarchidae) in dry forest in northwestern Madagascar. Folia Primatol 73:217

Neudorf DL, Sealy SG (2002) Distress calls in birds of a Neotropical cloud forest. Biotropica 34:118-126

Nishiumi N, Mori A (2015) Distance-dependent switching of antipredator behavior of frogs from immobility to fleeing. J Ethol 33:117-124

Noble DWA, Byrne RW, Whiting MJ (2014) Age-dependent social learning in a lizard. Biol Lett 10:20140430

Pollock HS, Martínez AE, Kelley JP, Touchton JM, Tarwater CE (2017) Heterospecific eavesdropping in ant-following birds of the Neotropics is a learned behaviour. Proc Royal Soc B 284:20171785

Potvin DA, Ratnayake CP, Radford AN, Magrath RD (2018) Birds learn socially to recognize heterospecific alarm calls by acoustic association. Curr Biol 28:2632-2637.e2634

Reyes-Olivares C, Labra A (2017) Emisión de sonidos en lagartos nativos de Chile: el estado del arte. Bol Chil Herpetol 4:1-9

Ruiz-Monachesi MR, Labra A (2020) Complex distress calls sound frightening: the case of the weeping lizard. Anim Behav 165:71-77

Russ JM, Jones G, Mackie IJ, Raceyp A (2004) Interspecific responses to distress calls in bats (Chiroptera: Vespertilionidae): a function for convergence in call design? Anim Behav 67:1005-1014

Shine R, Sun LX (2003) Attack strategy of an ambush predator: which attributes of the prey trigger a pit-viper's strike? Funct Ecol 17:340-348

Trigosso-Venario R, Labra A, Niemeyer HN (2002) Interactions between males of the lizard Liolaemus tenuis: roles of familiarity and memory. Ethology 108:1057-1064

Vitousek MN, Adelman JS, Gregory NC, StClair JJH (2007) Heterospecific alarm call recognition in a non-vocal reptile. Biol Lett 3:632-634

Young BA (2003) Snake bioacoustics: toward a richer understanding of the behavioral ecology of snakes. Quart Rev Biol 78:303-325

Young BA, Morain M (2002) The use of ground-borne vibrations for prey localization in the Saharan sand vipers (Cerastes). J Exp Biol 205:661-665

Publisher's Note Springer Nature remains neutral with regard to jurisdictional claims in published maps and institutional affiliations. 